\title{
CHANGES IN THE TOTAL POLYPHENOLIC CONTENT AND ANTIOXIDANT ACTIVITY OF FERMENTED MORINDA CITRIFOLIA L.
}

\author{
CHAIYAVAT CHAIYASUT ${ }^{1 *}$, BHAGAVATHI SUNDARAM SIVAMARUTHI ${ }^{1}$, PERIYANAINA KESIKA ${ }^{1}$, \\ SASITHORN SIRILUN ${ }^{1}$, KHONTAROS CHAIYASUT T ${ }^{2,3}$, RATTIKAN YOOSUPAP ${ }^{2}$, SARTJIN PEERAJAN ${ }^{2}$
}

${ }^{1}$ Innovation Center for Holistic Health, Nutraceuticals and Cosmeceuticals, Faculty of Pharmacy, Chiang Mai University, Chiang Mai 50200, Thailand. ${ }^{2}$ Health Innovation Institute, Chiang Mai 50230, Thailand. ${ }^{3}$ Institute of Research and Development, Chiang Mai Rajabhat University, Chiang Mai 50300, Thailand. Email:chaiyavat@gmail.com

Received: 01 February 2018, Revised and Accepted: 07 March 2018

ABSTRACT

Objective: The fermented plant beverages (FPBs) are considered as functional food. A detailed scientific investigation is required to develop functionally potential FPBs. The present study aimed to investigate the changes in total phenolic content and antioxidant properties of Lactobacillus paracasei HII01-mediated fermented Morinda citrifolia L. (noni) juice.

Methods: The fermentation media consist of 3:10:1 ratio of noni, water, and carbon source (either cane sugar or honey) along with $10 \%$ of inoculum (L. paracasei). The control samples were prepared without inoculum or substrate. The variations in $\mathrm{pH}$, acidity, total phenolic content, and the antioxidant capacity of the samples were kinetically measured by standard methods.

Results: The $\mathrm{pH}$ and total acidity of the samples were progressively reduced and improved when the duration of fermentation was prolonged, respectively. After 15 days of fermentation, F1 (1.198 mg GAE/ml sample) and F3 (1.265 mg GAE/ml sample) exhibited high total phenolic compound compared to other samples. Likewise, sample F3 displayed maximum antioxidant capacity. The samples with cane sugar exhibited high phenolic content, free radical scavenging activity, and chelating power than samples with honey.

Conclusion: About 15 days of fermentation in sufficient to obtain the high quality (rich in phenolic compounds and antioxidant capacity) fermented M. citrifolia juice using L. paracasei, and cane sugar as starter, and carbon source, respectively.

Keywords: Morinda citrifolia L., Lactobacillus paracasei, Fermented plant beverages, Phenolic content, Antioxidant.

(C) 2018 The Authors. Published by Innovare Academic Sciences Pvt Ltd. This is an open access article under the CC BY license (http://creativecommons. org/licenses/by/4. 0/) DOI: http://dx.doi.org/10.22159/ajpcr.2018.v11i6.25072

\section{INTRODUCTION}

Morinda citrifolia $\mathrm{L}$. is called as noni or Indian mulberry. Noni is commonly used in ancient foods and medicine. Noni fruits were comprised of carbohydrates, dietary fibers, vitamins (Vitamins C, E, B1, B2, B6, B12, biotin, pantothenic acid, folic acid, carotene, and niacin), proteins, minerals (calcium, potassium, sodium, phosphorus, iron, molybdenum, magnesium, and sodium chloride), and fat [1]. Almost all parts, such as fruits, leaves, roots, and barks, of noni plant have been used in the form of noni juice, powder, capsule, etc. The fermented noni juice is superior in terms of popularity, acceptability, and therapeutic reports [1]. Noni plant and its derivatives showed a robust therapeutic property against inflammation, infection, hypertension, cancer, ulcer, constipation, and autoimmune diseases [2-4].

The mechanism behind the health benefits of noni has been revealed in some extent. For example, limonene, quercetin, and alizarin in noni hinder the growth of the tumor cells and induce the apoptosis. Especially, quercetin suppresses the expression of PI3K/Akt/IKKalpha/NF-kappaB pathway genes [5,6]. Citrifolinoside present in noni inhibits the ultraviolet B-induced activator protein-1 activity [7]. Limonene is a monoterpene that exhibits anticancer ability [8]. The anti-inflammatory effects of noni are possibly due to the suppression of malondialdehyde by scopoletin through increased superoxide dismutase, glutathione peroxidase, and catalase activities [9].

The fermentation process positively improves the quality of fruit juice, especially lactic acid bacteria (LAB)-mediated fermentation enriched the functional property of the core ingredients [10]. The fermentation of plant materials with suitable LAB strain can supplement the functional qualities and health-enhancing abilities of the fermented beverages. For example, fermentation of mushroom with GABA producing LAB improved the quality and extended the application of the mushroom juices [11,12]. Lactobacillus spp. are a vital part of the human microbiome and are most studied bacterial probiotics. Lactobacillus brevis, Lactobacillus casei, Lactobacillus salivarius, Lactobacillus acidophilus, Lactobacillus fermentum, and Lactobacillus plantarum are often isolated from the intestinal tract of mammals. Even though live Lactobacillus are considered as safe for human consumption, they have been concerned as pathogens, particularly in the immunocompromised persons [13]. Lactobacillus spp. are commonly used for the preparation of fermented beverages because of simple growth conditions, and innocuous for the general population. The Lactobacillus-mediated fermentation improved the nutritional value of Phyllanthus emblica fruit juice [10], and Lactobacillus fermented plant juice has also been reported for cosmetic applications [14].

The present study was aimed to evaluate the impact of the fermentation process, mediated by Lactobacillus paracasei HII01, on the total polyphenol content and antioxidant capacity of M. citrifolia L. juice.

\section{METHODS}

Raw materials, strain, and experimental setup

Fresh M. citrifolia fruits and cane sugar were purchased from local market of Chiang Mai province, Chiang Mai, Thailand. Honey was bought from Agricultural Extension and Development Center, Chiang Mai. $L$. paracasei HII01 was obtained from Health Innovation Institute (HII), Chiang Mai. The controlled single strain fermentation of M. citrifolia was carried out with cane sugar, and honey as carbon source using $L$. 
paracasei as starter culture. The details of fermentation setup were described as follows:

Formula 1 (F1): M. citrifolia:water:cane sugar (3:10:1 ratio) $+10 \%$ L. paracasei

Formula 2 (F2): M. citrifolia:water:honey (3:10:1 ratio) +10\% L. paracasei Formula 3 (F3): M. citrifolia:water:cane sugar (3:10:1 ratio)

Formula 4 (F4): M. citrifolia:water:honey (3:10:1 ratio)

Control 1 (C1): Water:cane sugar (10:1 ratio) $+10 \%$ L. paracasei

Control 2 (C2): Water:cane sugar (10:1 ratio)

Control 3 (C3): Water:honey (10:1 ratio) $+10 \%$ L. paracasei

Control 4 (C4): Water:honey (10:1 ratio).

\section{Fermentation}

The preparation of starter culture, L. paracasei, and fermentation setup was done as defined earlier [10]. The fermentation was performed at $30 \pm 2^{\circ} \mathrm{C}$ for 6 months. Samples were collected during fermentation (day $0,4,7,10,15,20,30,45,60,75,90,120,150$, and 180). Then, they were filtered through Whatman no. 42 filter paper, $1 \%(\mathrm{v} / \mathrm{v})$ of each sample was aliquoted with sterile water and stored at $-70^{\circ} \mathrm{C}$

\section{Determination of acidity, $\mathrm{pH}$, and total polyphenolic content}

The $\mathrm{pH}$, acidity, and total polyphenolic content of fermented juice at various time points of fermentation were assessed as detailed previously $[10,15,16]$

\section{Total antioxidant capacity (TAC)}

TAC of fermented M. citrifolia juice was calculated by 2, 2'-azino-bis-3ethylbenzthiazoline-6-sulfonic acid assay as detailed previously $[17,18]$. Quercetin, trolox, and Vitamin C were used as standards. The results were represented as $\mathrm{mg}$ of quercetin equivalent antioxidant capacity (QEAC), mg of trolox equivalent antioxidant capacity (TEAC), and mg of Vitamin C equivalent antioxidant capacity (VCEAC)/ml of sample.

Ferric reducing antioxidant power (FRAP) and ferrous ionchelating assay

The FRAP assay and chelating property of the samples were studied as detailed [10]. The values of FRAP assay were represented as mg $\mathrm{FeSO}_{4}$ equivalents/ml sample. The chelating assay results were stated as chelating power ( $\mathrm{mg} \mathrm{FeSO}_{4}$ equivalents $/ \mathrm{ml}$ of sample)

\section{Statistical analysis}

Experiments were performed in triplicate. The values were denoted as mean \pm standard deviation. Duncan's new multiple range test determined the statistically significant differences, at the 95\% confidential level $(\mathrm{p}<0.05)$ by using SPSS v.17 (Chicago, SPSS Inc, U.S.A).

\section{RESULTS AND DISCUSSION}

The fermentation process was carried out in aseptic condition, and the collected samples were analyzed. The $\mathrm{pH}$ of $M$. citrifolia juice (formula 1-4) was gradually reduced from $4.15-3.86$ to 3.34-3.22. In the control fermentation setup also, $\mathrm{pH}$ of the solution was reduced (Fig. 1a).

The total acidity of F1 and F2 was increased from 0.1 to 0.64 , and 0.1 to $0.67 \mathrm{mg}$ lactic acid equivalent $/ \mathrm{ml}$ of sample, respectively. Likewise, the total acidity of F3 and F4 was increased from 0.08 to 0.67 , and 0.08 to $0.73 \mathrm{mg}$ lactic acid equivalent $/ \mathrm{ml}$ of sample, respectively. The control fermentation (C1, C2, C3, and C4) showed slight increase in acidity (from 0.09 to $0.48,0.08$ to $0.49,0.06$ to 0.23 , and 0.05 to 0.22 , respectively) (Fig. 1b). The changes in the $\mathrm{pH}$ and acidity level of the fermented samples were influenced by the carbon source (honey and cane sugar) and the presence of substrate (M. citrifolia). The control samples showed the shallow level of improvement in the acidity, possibly due to the lack of the substrate.

The total phenolic acid content of the fermented samples was evaluated. F1 and F3 showed high amount of phenolic content (1.198 and $1.265 \mathrm{mg} \mathrm{GAE} / \mathrm{ml}$ sample, respectively) after 15 days of fermentation, then the concentration was slightly reduced. However, at the end of the fermentation process, after 180 days, F1 and F3 showed high phenolic content ( 0.713 and $0.868 \mathrm{mg} \mathrm{GAE} / \mathrm{ml}$ sample, respectively) compared to other samples (Fig. 2). The control samples (C1 and C2) exhibited relatively high phenolic content than other control samples. The sample F1, F3, C1, and C2 contains cane sugar as a carbon source, while F2, F4, C3, and C4 having honey. The results suggested that the presence of cane sugar supports the growth of inoculum which facilitates the release of phenolic compounds from the substrate $M$. citrifolia. The antimicrobial property of honey may influence the growth of inoculum and other spontaneous microbial activity. The results suggested that fermentation of M. citrifolia with desired microbial starter culture and cane sugar facilitates the release of more phenolic compounds in the fermented broth compared to the samples with honey as a carbon source. Furthermore, the results revealed that the fermentation of M. citrifolia by $L$. paracasei for 15 days was enough to enrich the product with phenolic compounds.

The total antioxidant capacity (TAC) of the samples has been represented as TEAC, VCEAC, and QEAC. The sample F3 showed high TEAC of 0.62 , VCEAC of 0.76 , and QEAC of $0.36 \mathrm{mg}$ per $\mathrm{ml}$ of the sample after 15 days of fermentation, followed by F1 that displayed 0.47 , and $0.63 \mathrm{mg}$ TEAC and VCEAC per ml of sample. Whereas, F1 showed high QEAC value ( $0.28 \mathrm{mg}$ per ml of sample) after 75 days of fermentation. All the samples exhibited its high TAC value after 15 days of the fermentation process; even the control samples displayed the similar pattern after 15 days. Primarily, the experimental and control samples with cane sugar showed high TAC compared to honey counterparts. The data suggested that 15 days of fermentation was sufficient regarding TAC of samples (Fig. 3).

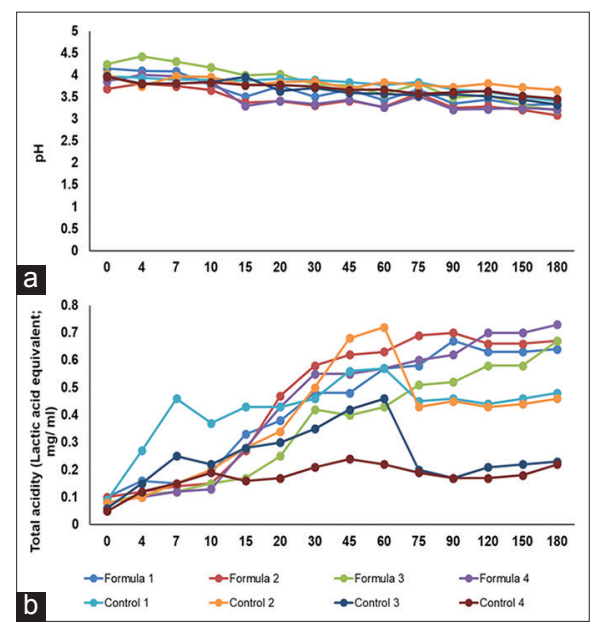

Fig. 1: The pH profile (a) and total acidity (b) of fermented samples. The $\mathrm{pH}$ values were gradually decreased while the acidity was increased in a time-dependent manner

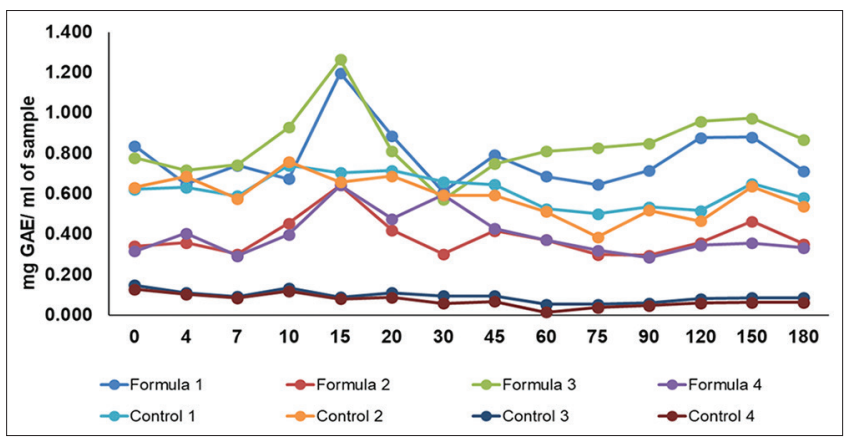

Fig. 2: The changes in total phenolic content of fermented Morinda citrifolia. The phenolic content was represented as mg $\mathrm{GAE} / \mathrm{ml}$ of sample 
Ferric reducing antioxidant power of F1, F2, F3, and F4 were 1.2, 0.6, 1.9 , and $0.7 \mathrm{mg} \mathrm{FeSO}_{4}$ equivalents per $\mathrm{ml}$ of sample, respectively. The control samples $\mathrm{C} 1, \mathrm{C} 2, \mathrm{C} 3$, and C4 were $1.3,1.1,0.1$, and 0.1 mg FeSO equivalents per $\mathrm{ml}$ of sample, respectively, after 15 days of fermentation (Fig. 4a). The chelating power of F1, F2, F3, and F4 was 87.0, 88.4, 87.6, and $88.8 \mathrm{mg} \mathrm{FeSO}_{4}$ equivalents per ml of sample, respectively. The control samples C1, C2, C3, and C4 were 84.1, 83.1, 86.3, and $85.8 \mathrm{mg} \mathrm{FeSO}_{4}$ equivalents per ml of sample, respectively, after 15 days

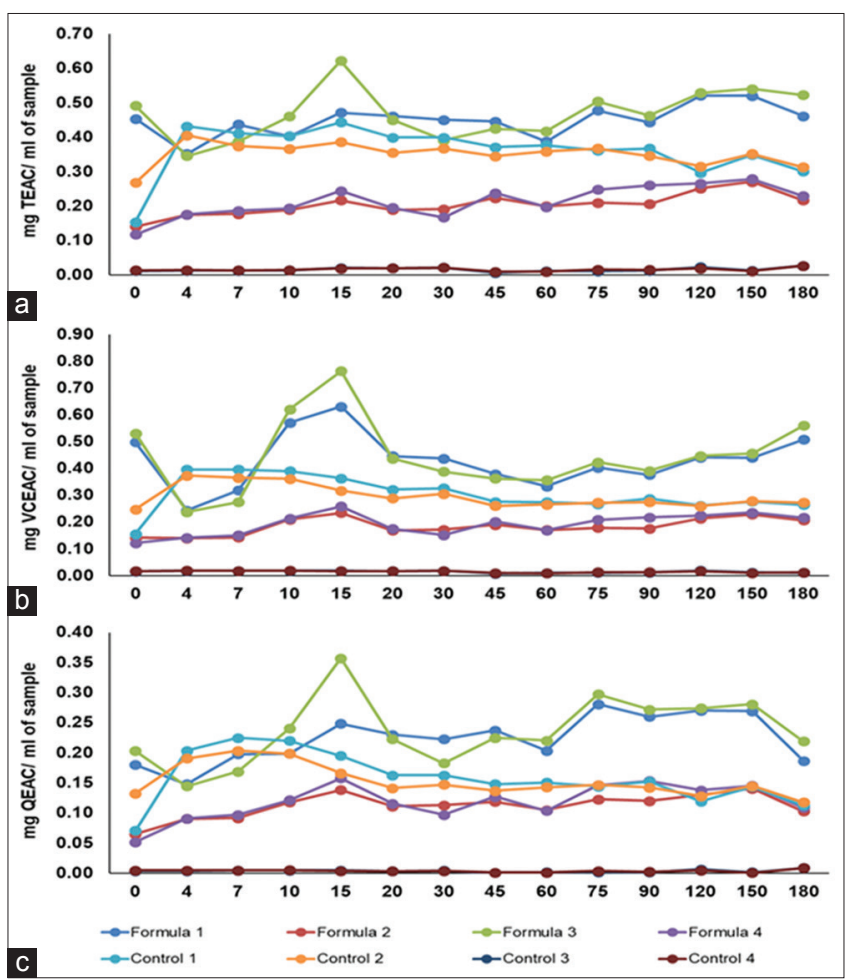

Fig. 3: The total antioxidant capacity of fermented Morinda citrifolia juice and values were represented as mg trolox equivalent antioxidant capacity (a), Vitamin C equivalent antioxidant capacity (b), and quercetin equivalent antioxidant capacity (c) per $\mathrm{ml}$ sample

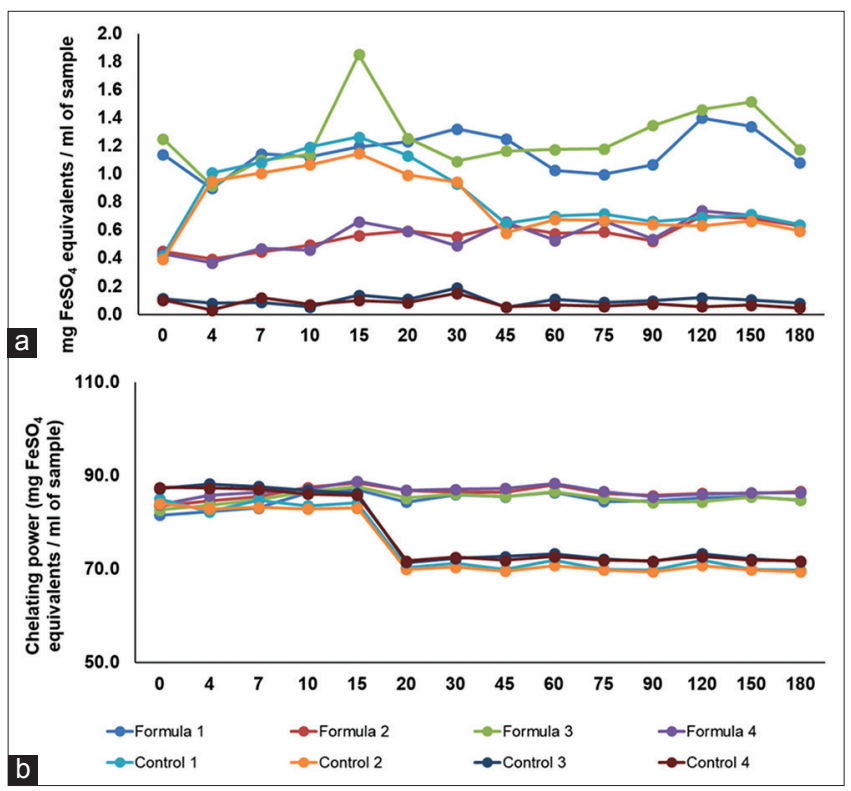

Fig. 4: Ferric reducing antioxidant power (a) and chelating power (b) of fermented Morinda citrifolia juice of fermentation (Fig. 4b). The high chelating power of the samples was observed after 15 days of fermentation. The FRAP and chelating power of the test samples were significantly retained up to 180 days of fermentation, whereas in control samples the values were reduced gradually during the process.

The phenolic compounds in methanolic extract of M. citrifolia have been affected by the temperature and pressure used during the extraction. At $70^{\circ} \mathrm{C}$, the total phenolic content was decreased in methanolic extract of noni, possibly due to the denaturation of phenolics at high temperature while total flavonoids content was not affected [19]. The bioactivity, total flavonoid, and phenolic content of $M$. citrifolia fruit extract were affected by high-pressure extraction, and drying methods [20].

Yang et al. [21] reported the influence of storage conditions on the phytochemical content and antioxidant property of noni juice and noni powder. The results revealed that storage of noni juice and powder in dark bottle at $24^{\circ} \mathrm{C}$ retains the functional property up to 3 months.

Hafiza et al. [22] reported the changes in $\mathrm{pH}$, acidity, and phenolic content of Saccharomyces cerevisiae-mediated fermented noni. The study suggested that the increase in substrate and fermentation time has a positive impact on acidity. The increased fermentation time negatively affects the phenolic content of fermented noni juice. Whereas, the increase in substrate concentration directly proportional to the total polyphenol content of fermented M. citrifolia extract [22]. Moreover, Hafiza et al. [22] reported that after 6 days of fermentation, the total phenolic content level was gradually reduced in noni extract.

The results of the present study also suggested that the substrate and carbon source in the fermentation medium influence the total acidity, phenolic content, and antioxidant property of fermented noni juice. Honey may have the antagonistic activity against starter culture. The presence of cane sugar promoted the growth of L. paracasei (data not showed) that facilitates the release of more phytochemical from M. citrifolia.

Several studies reported the health benefits of noni extracts. Noni extract has been reported for antidiabetic, antitubercular property $[23,24]$. The noni extract has been proved as a functional food supplement to treat infections, inflammatory diseases, and oxidative stress [25]. The face mask prepared with $0.1 \%$ of ethanolic extract of M. citrifolia was a natural nutracosmeceutical product with antiwrinkle property [26]. The naturally fermented noni aqueous extract exhibited antidiabetic, and hepatoprotective activity in diabetic rats [27]. The probiotic, L. paracasei HII01 mediated fermented noni juice might be a potent nutraceutical candidate for the betterment of human health.

\section{CONCLUSION}

L. paracasei HII01-mediated fermented of M. citrifolia fruits juice was enriched with phenolic compounds and antioxidants. The use of cane sugar as carbon source for the growth of L. paracasei HII01 facilitates the fermentation process compared to honey. Likewise, the study suggested that natural fermentation of noni with cane sugar was found to be relatively superior like $L$. paracasei HII01-mediated fermented juice. However, the use of probiotic strains as starter culture for the development of fermented juices may enhance the product quality with added benefits of probiotics.

\section{ACKNOWLEDGMENT}

Authors gratefully acknowledge Chiang Mai University grant (CMUgrant) for the support. Authors also thankfully acknowledge the Faculty of Pharmacy, and Chiang Mai University, Thailand, for the support and instrumentation facilities.

\section{AUTHOR'S CONTRIBUTIONS}

CC involved in the study design, experiments, review, and finalization of the manuscript. BSS and PK contributed to data analysis, manuscript 
preparation, and critical revision of the manuscript. SS, KC, RY, and SP responsible for wet lab experiments and data collection. All the authors agree with the content of the manuscript.

\section{CONFLICT OF INTEREST}

There is no conflict of interest.

\section{REFERENCES}

1. Ali M, Kenganora M, Manjula SN. Health benefits of Morinda citrifolia (Noni): A review. Phcog J 2016;8:321-34.

2. Wang MY, Su C. Cancer preventive effect of Morinda citrifolia (Noni). Ann N Y Acad Sci 2001;952:161-8

3. Wang MY, West BJ, Jensen CJ, Nowicki D, Su C, Palu AK, et al. Morinda citrifolia (Noni): A literature review and recent advances in noni research. Acta Pharmacol Sin 2002;23:1127-41.

4. Kamiya K, Tanaka Y, Endang H, Umar M, Satake T. Chemical constituents of Morinda citrifolia fruits inhibit copper-induced lowdensity lipoprotein oxidation. J Agric Food Chem 2004;52:5843-8.

5. Hornick CA, Myers A, Sadowska-Krowicka H, Anthony CT, Woltering EA. Inhibition of angiogenic initiation and disruption of newly established human vascular networks by juice from Morinda citrifolia (noni). Angiogenesis 2003;6:143-9.

6. Sun ZJ, Chen G, Hu X, Zhang W, Liu Y, Zhu LX. Activation of PI3K Akt/IKKalpha/NF-kappa B signaling pathway is required for the apoptosis-evasion in human salivary adenoid cystic carcinoma: Its inhibition by Quercetin. Apoptosis 2010;15:850-63.

7. Sang S, Kan H, Guangming L Nanqun Z, Mingfu W, Jhoo JW. Citrifolinin A, a new unusual iridoid with inhibition of activator protein-1 (AP-1) from the leaves of noni (Morinda citrifolia L.). Tetrahedron Lett 2001;42:1823-5.

8. Hohl RJ. Monoterpenes as regulators of malignant cell proliferation. Adv Exp Med Biol 1996;401:137-46.

9. Chang TN, Deng JS, Chang YC, Lee CY, Jung-Chun L, Lee MM, et al. Ameliorative effects of scopoletin from crossostephium chinensis against inflammation pain and its mechanisms in mice. Evid Based Complement Alternat Med 2012;2012:595603

10. Peerajan S, Chaiyasut C, Sirilun S, Chaiyasut K, Kesika P, Sivamaruthi BS. Enrichment of nutritional value of Phyllanthus emblica fruit juice using the probiotic bacterium, Lactobacillus paracasei HII01 mediated fermentation. Food Sci Technol Campinas 2016;36:116-23.

11. Woraharn S, Lailerd N, Sivamaruthi BS, Wangcharoen W, Peerajan S, Sirisattha S, et al. Development of fermented Hericium erinaceus juice with high content of L-glutamine and L-glutamic acid. Int J Food Sci Technol 2015;50:2104-12.

12. Woraharn S, Lailerd N, Sivamaruthi BS, Wangcharoen W, Sirisattha S, Peerajan S, et al. Evaluation of factors that influence the L-glutamic and $\gamma$-aminobutyric acid production during Hericium erinaceus fermentation by lactic acid bacteria, CyTA. J Food 2016;14:47-54

13. Slover CM, Danziger L. Lactobacillus: A review. Clin Microbiol News1 2008;30:23-7.
14. Sirilun S, Sivamaruthi BS, Kumar N, Kesika P, Peerajan S, Chaiyasut C. Lactobacillus-fermented plant juice as a potential ingredient in cosmetics: Formulation and assessment of natural mouthwash. Asian J Pharm Clin Res 2016;9 Suppl 3:52-6.

15. Chaiyasut C, Makhamrueang N, Peerajan S, Sivamaruthi BS. Assessment of organic acid content, and brix value of representative indigenous fermented plant beverages of Thailand. Asian J Pharm Clin Res 2017;10:350-4.

16. Chaiyasut C, Kesika P, Chaiyasut K, Sittiyuno P, Peerajan S, Sivamaruthi BS. Total phenolic content and free radical scavenging activity of representative medicinal plants of Thailand. Asian J Pharm Clin Res 2017;10:137-41.

17. Sivamaruthi BS, Pengkumsri N, Saelee M, Kesika P, Sirilun S, Peerajan $\mathrm{S}$, et al. Impact of physical treatments on stability and radical scavenging capacity of anthocyanidins. Int J Pharm Pharm Sci 2016;8:162-7.

18. Chaiyasut C, Sivamaruthi BS, Pengkumsri N, Sirilun S, Peerajan S, Chaiyasut $\mathrm{K}$, et al. Anthocyanin profile and its antioxidant activity of widely used fruits, vegetables, and flowers in Thailand. Asian J Pharm Clin Res 2016;9:218-24.

19. Krishnaiah D, Bono A, Sarbatly R, Anisuzzaman SM. Antioxidant activity and total phenolic content of an isolated Morinda citrifolia L. Methanolic extract from Poly-ethersulphone (PES) membrane separator. J King Saud Univ Eng Sci 2015;27:63-7.

20. Ramamoorthy PK, Bono A. Antioxidant activity, total phenolic and flavonoid content of Morinda citrifolia fruit extracts from various extraction processes. Int J Eng Sci 2007;2:70-80.

21. Yang J, Gadi R, Paulino R, Thomson T. Total phenolics, ascorbic acid, and antioxidant capacity of noni (Morinda citrifolia L.) juice and powder as affected by illumination during storage. Food Chem 2010;122:627-32.

22. Hafiza ZN, Maskat MY, Liew SL, Mamot S. Fermentation of Morinda citrifolia extract by Saccharomyces cerevisiae as affected by substrate concentration, inoculum size, temperature and fermentation time. Int Food Res J 2013;20:1889-94

23. Lee SY, Park SL, Hwang JT, Yi SH, Nam YD, Lim SI, et al. Antidiabetic effect of Morinda citrifolia (Noni) fermented by cheonggukjang in $\mathrm{KK}-\mathrm{A}(\mathrm{y})$ diabetic mice. Evid Based Complement Alternat Med 2012;2012:163280.

24. Mauliku NE, Hendro W, Saputro SH, Kristina TN. Anti-tubercular activity of extract and compounds of noni (Morinda citrifolia Linn). Int J Pharm Pharm Sci 2017;9:105-9.

25. Mueller M, Puttipan R, Janngeon K, Unger FM, Viernstein $H$, Okonogi S. Bioactivities of the Thai medicinal and edible plants C. cajan, M. citrifolia and O. americanum. Int J Pharm Pharm Sci 2015;7:237-40.

26. Surini S, Auliyya A. Formulation of an anti-wrinkle hydrogel face mask containing ethanol extract of noni fruit (Morinda citrifolia $\mathrm{L}$ ) for use as a nutracosmeceutical product. Int J App Pharm 2017;9 Suppl 1:74-6.

27. Nayak BS, Marshall JR, Isitor G, Adogwa A. Hypoglycemic and hepatoprotective activity of fermented fruit juice of Morinda citrifolia (Noni) in diabetic rats. Evid Based Complement Alternat Med 2011;2011:875293. 